\title{
Review on Automotive Power Generation System on Plug-in Hybrid Electric Vehicles \& Electric Vehicles
}

\author{
Yap Wee Leong ${ }^{1}$, a Akhtar Razul Razali ${ }^{1}$, Gigih Priyandoko ${ }^{1}$ and Nazrul Idzham Kasim ${ }^{1}$ \\ ${ }^{1}$ Faculty of Mechanical Engineering, Universiti Malaysia Pahang, Malaysia
}

\begin{abstract}
Regenerative braking is a function to recharge power bank on the Plug-in electric vehicles (PHEV) and electric vehicles (EV). The weakness of this system is, it can only perform its function when the vehicle is slowing down or by stepping the brake foot pedal. In other words, the electricity recharging system is inconsistent, noncontinuous and geography dependent. To overcome the weakness of the regenerative braking system, it is suggested that to apply another generator which is going to be parallel with the regenerative braking system so that continuous charging can be achieved. Since the ironless electricity generator has a less counter electromotive force (CEMF) comparing to an ironcored electricity generator and no cogging torque. Applying the ironless electricity generator parallel to the regenerative braking system is seen one of the options which creates sustainable charging system compared to cored electricity generator.
\end{abstract}

\section{Research Background}

Non-renewable energy depletion is an undeniable fact over the decade. The consumption of non-renewable energy keep on increasing makes the non-renewable energy deplete faster than expected. Obviously, fossil fuels are natural resources that are not renewable and will be exhausted in the near future.

Unlike the old days, only internal combustion engine (ICE) was used in the past few ten years ago [1]. With the rising concern in environment issue that is facing globally, the automobile is required to be cleaner and more efficient. [2]. The development of hybrid vehicles (HEV) as well as plug-in hybrid vehicles (PHEV) technologies had been carried out intensively by nearly all car manufacturers and researchers around the globe for the last 5 years. The industries of automotive have introduced the hybrid car, for example, Honda Insight and Toyota Prius which allows the vehicles to minimize the usage of ICE by integrating them with an electric motor. [3]. For instance, a hybrid vehicles (HEV), when the battery is running low, the internal combustion engine (ICE) will be the main power source for the vehicle to move and at the same time, the engine charges the battery while moving. While for the plug-in hybrid vehicles (PHEV), it totally depends on the battery of the vehicles. The depleted battery is then charged at a charging station to top up the battery energy.

Although the demand of the HEV and PHEV is increasing, the increment of charging station is not

\footnotetext{
${ }^{\mathrm{a}}$ Corresponding author: weeleong99@hotmail.com
}

proportional with respect to these vehicles. Not many charging stations are built to cater the charging demand. One of the reasons why, is, to avoid electrical surge issue. Research elsewhere had shown that if the usage of the EVs increases to $30 \%$, there will be $54 \%$ of increment for the national peak load when uncoordinated charging is practiced [4]. This makes the developing of the charging station possesses a risk to the National Grid potential supply. Other than that, developing the charging station required high capital and involved the whistleblowers and policymakers to debate the policies and its mechanism.

The PHEV and EV are not just only charged by plugged-in, it is also able to charge during onboard using the system that is embedded on it. It is called a regenerative braking charging system. The regenerative braking charging system only happen when the vehicle is slowing down and during braking or when there is no force applied on the acceleration pedal [5]. The charging is based on the concept of making use of the cogging torque and counter electromotive force (CEMF) resistance produced by the motor and capture the wasted energy during coasting downhill or during braking to produce electricity which is stored in an ultra-capacitor. In other words, the motor of the vehicle act as an accelerator during acceleration and act as a generator during deceleration. However, the common foot-pedaled hydraulic brake is still in use to assist the braking. However, in a real driving situation, there will not be downhill and braking all the way, or simply say, this kind of charging process are non-continuous, non-sustainable, 
geography dependent and will greatly affect the driving range efficiency.

To overcome the non-continuous charging issue of the regenerative braking system, a system which mainly found in the wind power generation technologies, ironless electricity generator [6] is seen as a promising solution to capture energy during in motion. Ironless electricity generator has low starting torque, higher efficiency and can produce the considerable amount of electricity based on the size of the generator itself. This type of generator has no cogging effect and low CEMF resistance [7] when producing electricity because the generator itself doesn't have the iron core lamination which can be found in the ironcored electricity generator. The ironcore used in the cored system causes magnetic field between the ironcore and the permanent magnet to resist the motion. It can be concluded that the ironless design requires less energy to spin and basically it is practical to be used as an additional generator in PHEVs and EVs.

\section{Literature Review}

Several literature reviews had been done in the area within this research. For part 2.1, it will discuss the nonrenewable energy and the crisis cause by it. As for the part 2.2, discussion about the present response to the crisis. For part 2.3, it discuss the demand and projection for the hybrid vehicles which is further divided into 5 parts namely example of EV, HEV and PHEV, demand and projection of PHEV and EV, characteristic of HEV and EV, charging mechanism of PHEV and EV as well as issue faced by PHEV and EV. As for the part 2.4, the regenerative braking and energy captured/produced is discussed. While for part 2.5, approaches taken to address the issue to boost mileage for EV and PHEV and for this part, system efficiency, advantage/disadvantage comparison between cored and coreless electricity generator is summarized. Lastly, coreless generator design and performance is discussed in part 2.6.

\subsection{Non-renewable energy and its crisis}

Natural resources normally found in the specific area, thus grievances are more prone towards open conflicts. Study shows that Europe dependence on foreign sources for more than $80 \%$ of its oil and reserves of conventional oil are increasingly concentrated in the politically unstable area. [8] The consumption of non-renewable energy such as petroleum and diesel is an issue since it involves the price of the oil and securities of oil supplies. [9]. From a research elsewhere, there are around 1 billion units of the automobile in use around the worldwide daily [10]. According to some estimation, more than one per five conflicts worldwide is based on the resources conflict [6]. The usage of petroleum and diesel also will produce greenhouse gas (GHG) and other air pollutants such as $\mathrm{NO}_{\mathrm{x}}, \mathrm{PM}_{10}$ and volatile organic compounds [11], representing the leading anthropogenic cause of global climate change [12]. On late of the year 2011, there are 7 billion inhabitants around the world and it is estimated to increase to 9 billion in 40 years' time, which means that it will obviously give an impact on climate change and energy security [1].

\subsection{Present response to the crisis}

To counter the non-renewable energy crisis which is experiencing worldwide, such as pollution caused by usage of non-renewable energy, there are several technologies those had been under developed or been developed so that it can help to reduce dependency on non-renewable energy. Renewable energy technology is one of the methods which currently being widely explored in many countries. Examples of renewable energy technologies are tidal energy harvesting in the ocean, a wind turbine to harvest energy via the wind and the development of hybrid vehicles to reduce fuel dependency. With the rising concern in environment issue which is faced globally, automotive is required to be cleaner and more efficient [2].

Governments around the globe have identified electrified transportation industries as a strategic planning for national security. [13]. It did increases the enthusiasm in investment and research for alternative fuel vehicles (AFVs). [14]. The hybrid vehicles or electric vehicles those are powered by renewable energies, which only emit natural byproducts but not exhaust fumes is able to improve the air qualities and thus improve the health of peoples. [15]. It is because with the hybrid vehicles or electric vehicles that powered by renewable energies, which only emit natural byproducts but not exhaust fumes is able to improve the air qualities and thus improve the health of peoples. [15]. Also, the cost and benefits for potential benefits have been pointed out in various research. [16-17]. Research elsewhere takes the Portuguese power system as an example, a potential $23 \%$ decrease in $\mathrm{CO}_{2}$ as well as $31 \%$ increment on $\mathrm{H}_{2} \mathrm{O}$ emissions are forecasted if the $\mathrm{PHEVs} / \mathrm{EVs}$ are widely used. [18].

In the State of Union address made by the President of America, President Obama's 2011, he had called for putting one million units of electric vehicles on the road by the year 2015, an affirming and highlighting goal aim to build United States leadership in technologies which can help to reduce the dependence on oil [19]. With this kind of rate of penetration, PHEVs would carry about $2.5 \%$ of all new vehicles sales in 2015. [20]. For China, according to their government's plan, they will be investing 100 billion RMB in new energy vehicles, which includes PHEVs, HEVs, EVs as well as other types of new energy vehicles on the road. This is an attempt to make China as the largest green vehicles inventory by 2020 which their inventory might be as large as 5 million units of green vehicles. [21]. The European Union (EU) also in progress to making their nation a greener one by develop a roadmap which defines the development of PHEVs/EVs in EU through a three-stage program that aim to set 5 million green vehicles on the road in next decade. [22]. Other than that, Japan [23] and Korea [24] also had their plan to making their country greener by devising their plan for new green vehicles development. 
Transportation electrification also will bring up future energy revolution, reshaping the traditional view of the industrial power system. [25].

\subsection{Demand and Projection of hybrid vehicles}

\subsubsection{Example of HEV, PHEV and EV}

Toyota, one of the key automobile manufacturers around the world, is also putting their money on this research field. Not only Toyota, in fact, both Honda and Nissan of Japan, BMW and Volkswagen of the Europe, as well as Chevrolet and Tesla of the USA, they are all investing their money towards maturing their EVs and PHEVs technologies. The results of the researches are the high end PHEVs such as Toyota Prius, a hybrid electric vehicle by Toyota [26] Jetta Hybrid, made by Volkswagen [27] and Honda CR-Z by Honda [28], Chevrolet Volt by Chevrolet [29], and BMW i8 by BMW [30]. Nissan Leaf [31] and Tesla Model S [32] are grouped in the solely electric vehicles both developed by Nissan and Tesla respectively.

For Toyota, they were able to develop a set of hybrid car technologies called Hybrid Synergy Drive (HSD) which combines an electric drive and a continuously variable transmission with no direct mechanical connection between the engine and the engine control, which makes the gas pedal and the gearshift lever in an HSD car send electrical signals to a control computer. HSD replaces the gear box, alternator and starter motor with a pair of electrical motor-generators which normally being called as MG1 and MG2, a computerized shunt system to control MG1 and MG2, a mechanical power splitter that function as second differential, and a battery pack that serves as an energy reservoir. The function of each MG is to convert electricity to mechanical power or vice-versa [33]. The regenerative braking system that applied in the Toyota Prius is based on an electric hydraulic brake system [34] and this system utilizes both motor from the regenerative braking motor and hydraulic braking to stop the vehicles. [35]

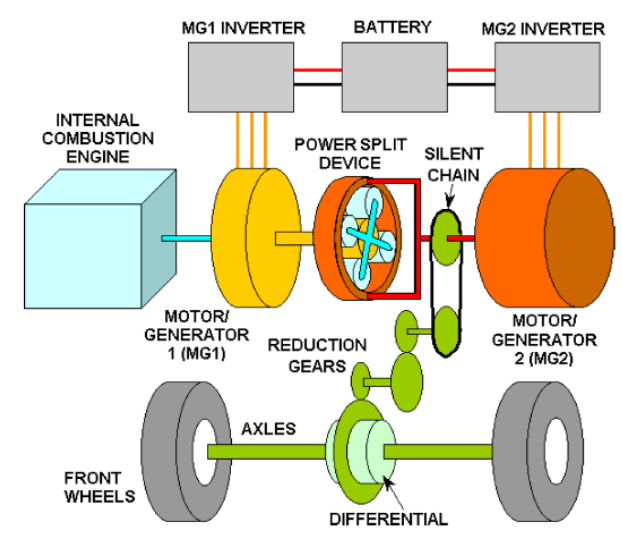

Figure 1. Schematic diagram for Toyota's Hybrid Synergy Drive (HSD)

For Honda, they choose a simple parallel hybrid design because they think that it can be made lighter and thus helps to improve vehicle performance and fuel efficiency. Since the engine serves as the main power source, engine power and electric motor power can be transmitted to the wheels directly. The motor and engine works together in the different driving situation. For example, during standing starting, electric motors offer maximum torque but as motor speed increases, torque output decreases, while on the other hand, the engine torque output only starts to increase above a certain engine speed, thus combining motor assistance with an engine give the better efficiency. During deceleration, the vehicle's kinetic energy is recovered and converted into electricity via motor/generator and this electricity is stored in batteries and used to power the motor in later time [36].

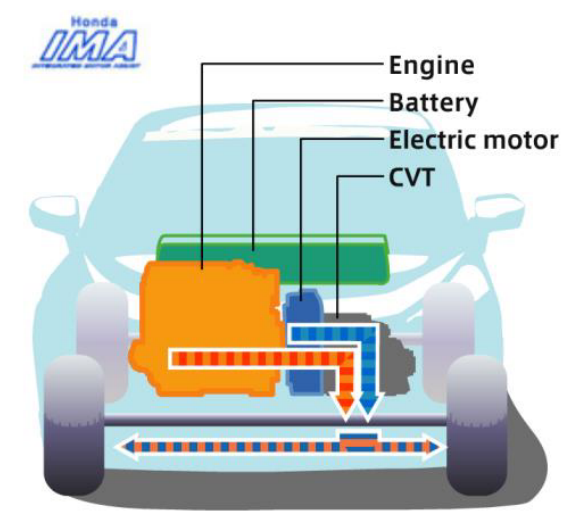

Figure 2. Schematic diagram for Honda's Integrated Motor Assist (IMA)

For BMW, their hybrid system, ActiveHybrid, is a combination of their six-cylinder petrol engine, an electric engine and a lithium-ion battery which coordinated by intelligent energy management system. The electric engine allows the vehicle is driving with pure electric energy below $60 \mathrm{~km} / \mathrm{h}$ for around 3 to $4 \mathrm{~km}$. The electric engine also helps the ICE during overtaking, inclined route and other driving situation like sudden acceleration as well as in gliding mode. Their Brake Energy Regeneration, regenerative braking system within the BMW, allows the vehicles to save energy into the lithium-ion battery during braking or decelerates [37].

\subsubsection{Demand and Projection for PHEV and EV}

In the BLUE maps scenario, one of the energy policy scenario in International Energy Agency (IEA) Energy Technology Perspectives analysis, aim to achieve 50\% global $\mathrm{CO}_{2}$ emission reduction from 2005 levels by 2050 , was revised in 2009 to account both for the economic crisis that began in 2008, which decreased projected car sales, as well as for PHEV and EV product plans announced since the ETP was published, which suggest the possibility of a higher level of EV sales through 2020 [38]. Moreover, if using a moderate market penetration scenario, the Electric Power Research Institute (EPRI) 
projected around $62 \%$ of whole U. S. vehicles numbers are of the PHEVs/EVs by 2050 [39].

In the Malaysia's National Automotive Policy (NAP) 2014, the government targets for Malaysia to become regional hub for Energy Efficient Vehicles (EEV) through strategic investments as well as adaption on the high technology for domestic market and penetrate regional and global markets by 2020 . NAP 2014 also will align the automotive industry development to future technology direction and promote investments in green automotive technologies. The initiatives that will be taken are to increase the utilization of green technologies, enhance strategic collaboration between Malaysia and its Free Trade Agreement (FTA) partners, enhance expertise in the areas of research, design and development and provides relevant infrastructure and enabler for development of green technology [40].

One of the roadmaps mentioned in the NAP 2014 which is the Malaysia Automotive Technology Roadmap (MATR), has been developed to complement the execution of the NAP 2014. The roadmap serves as a guideline to achieve the transformation objective of the local automotive industry. The MATR entails the latest green technologies development that are in the line with the development of the global automotive industry. The figure shows that the forecast evolution of green technologies in future time while for the Figure shows the Malaysia automotive technology projection in 2013 to 2025 which analyzed by Malaysia Automotive Institute (MAI) [41]. It is expected that the PHEVs/EVs will be more frequently used since the public awareness for these kinds of vehicles is growing. [42]. The usage of HEVs, PHEVs and EVs in the passenger vehicle market will involve meaningful shift in social and technologies [43].

\subsubsection{Characteristic of HEV and EV}

Although the electric vehicles and hybrid electric vehicles look similar, but inside them, there are a little difference within themselves. For example, EVs is powered by the electric motor while for the HEVs, it is powered by electric motor and back up by internal combustion engine. For energy system inside the electric vehicles, it used battery and ultracapacitor as energy source while for the hybrid electric vehicles, not only batteries and ultracapacitors were used as an energy source, but it has additional internal combustion engine to charge the energy banks.

In terms of energy source and infrastructure in order to power up the electric vehicles, the electric grid charging facilities is required to do the charging. While for the hybrid electric vehicles, it requires gasoline stations. In terms of characteristics, electric vehicles have zero emissions, high energy efficiency, independence on crude oils, has the short driving range and expensive compared to normal vehicles. While for the hybrid electric vehicles, it has very low emission compare to normal ICE vehicles, has higher fuel economy compared to ICE powered vehicles, has long driving range, dependency on crude oil since is still required to power up its internal combustion units, slightly higher cost compare to normal ICE vehicles and increase in fuel economy and reduce in emission depending on the power level of motor and battery as well as driving cycle. Moreover, PHEVs/EVs had shown the much lower lifecycle cost compare to either hydrogen fuel cell as well as an internal combustion engine. [44].

There is some weakness in electric vehicles and hybrid electric vehicles. For electric vehicles, it battery and battery management is quite an issue since it required a just battery to power up whole vehicles. The lack of charging facilities and higher initial cost also the weaknesses of the hybrid vehicles. For hybrid electric vehicles, some efforts need to be made since multiple energy sources control including electric and petroleum to power up the vehicles, optimization and management of these 2 energy sources can be quite complicated. Battery sizing and management of battery is also a weakness for hybrid electric vehicles since it required to compact the size of the battery. [45].

\subsubsection{Charging Mechanism of PHEV and EV}

Within PHEV and EV themselves, the batteries cannot be charged when at a certain condition, for example during accelerating/coasting. The batteries can only be charged when no power input is given to the vehicle, for instance, during deceleration and braking. This function is called regenerative braking system. As one of the key technologies embedded in the electric vehicles, regenerative braking concepts those applied in various type of vehicles such as electric vehicles (EV), hybrid electric vehicles (HEV) as well we plug-in hybrid vehicles (PHEV) result in an effective improvement in

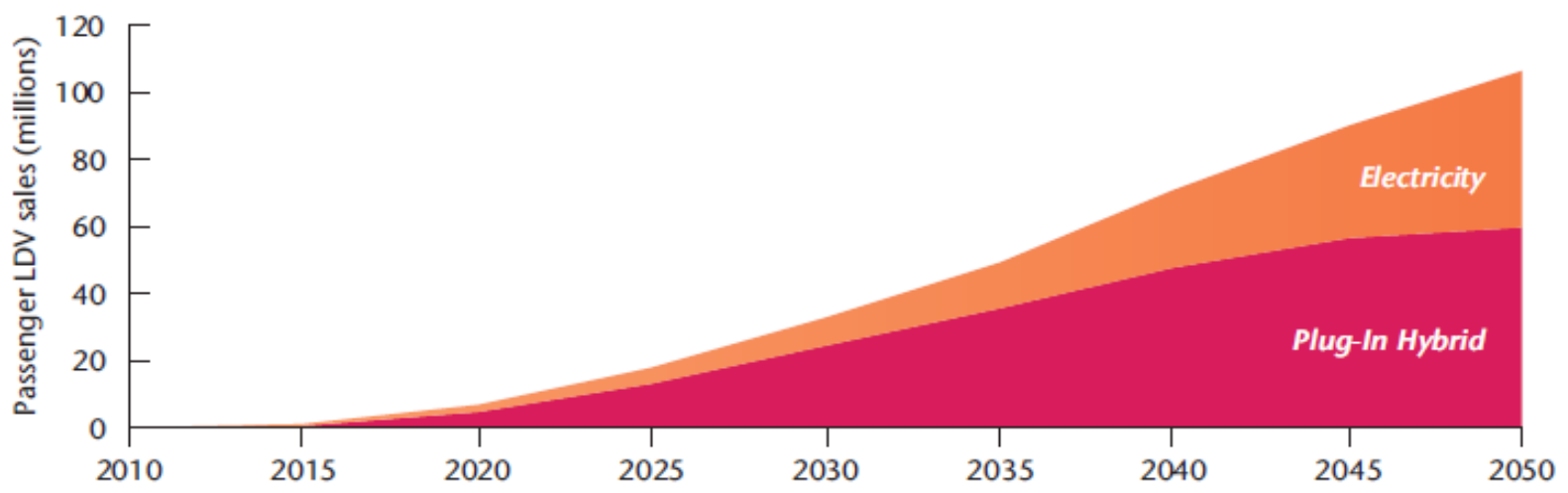

Figure 3. Expected annual sales for EV and PHEV in BLUE maps scenario 
the fuel economy by recuperating the braking energy. [46]. Regenerative braking paired with the use of ultracapacitors for energy storage purpose could reduce the fuel consumption of conventional ICE vehicles significantly and it can be deployed in the immediate future. [5]. During braking for normal vehicles, the frictional force made between braking pad and braking disc became heat and dissipated to the surrounding. For the hybrid electric vehicles which had implemented the regenerative braking system, it recovers some of the kinetic energy via the electric motor and stores it as electrical energy in high voltage batteries. It is because during braking, the vehicle's electric motor acts as a generator, producing electricity and charge the high voltage batteries. The charging is based on the concept of making use of the cogging torque and counter electromotive force (CEMF) resistance produced by the motor and capture the wasted energy during coasting downhill or during braking to produce electricity which is stored in an ultra-capacitor. In other words, the electric motor acts as a motor to assist ICE during acceleration and act as a generator during deceleration.

\subsubsection{Issue Faced by PHEV and EV}

\subsubsection{Electricity for Charging the PHEV and EV}

Although the demand of the HEV and PHEV is increasing, the increment of charging station is not proportional with respect to these vehicles. Not many charging stations are built to cater the charging demand. One of the reasons why is, to avoid electrical surge issue. Research elsewhere had shown that if the usage of the EVs increases to $30 \%$, there will be $54 \%$ of increment for the national peak load when uncoordinated charging is practiced [4]. Developing the charging station required high capital and involved the whistleblowers and policymakers to debate the policies and its mechanism. Thus, increases the difficulties on the development of the charging station for PHEV and EV. When a larger user community of PHEVs/EVs, they will required more electricity to charge the PHEVs/EVs. When a large number of PHEVs/EVs is plugged into a system randomly, significant uncertainties will be introduced into the system. [47]. There will be an issue if a large number of PHEVs/EVs are connected to the grid at the same time which it may pose a huge threat to the quality and the stability of the overall power system. [48-49]. Also, with the market penetration of PHEVs/EVs, it is likely to change the configuration of the power system. [50].

\subsubsection{Non-continuous Charging Issue Faced by Regenerative Braking System}

The regenerative braking charging system is one of the promising solutions in terms of electrical charging on the

\footnotetext{
${ }^{\mathrm{a}}$ Corresponding author: weeleong99@hotmail.com
}

EVs and PHEVs. This is achieved by converting kinetic energy into electrical energy. However it only happens when the vehicles are slowing down and during braking or when there is no force applied on the acceleration pedal [5]. Logically, it is not possible to have a journey completely going downhill all the way throughout the driving period. In another word, this charging system is not able to perform continuous charging.

\subsection{Regenerative Braking and Energy Capture/Produced}

Studies shows that during urban driving, there are about one third to one half of the energy from the power plant that produce electricity for daily usage is discarded to the atmosphere in the form of heat by a conventional braking system while performing deceleration. [51]. In real life, this scenario is not favorable since the heat energy is also a source of energy which originally comes from kinetic energy [52]. To avoid from happening, the regenerative braking system is used to capture the wasted kinetic energy, converts it into electric energy and charge the on board batteries or ultracapacitor.

The key technologies of electric vehicles, which is the regenerative braking system, give the results improvement in the fuel economy by recuperating the braking energy. [45]. During braking for normal vehicles, friction between braking pad and disc generates heat and dissipates to the surrounding. For the hybrid electric vehicles equipped with the regenerative braking system, it recovers some of the kinetic energy via the electric motor and stores it as electrical energy in high voltage batteries. It is because during braking, the vehicle's electric motor acts as a generator, producing electricity and charge the high voltage battery. [53]. It did recapture kinetic energy during deceleration of the vehicles and significantly improved the energy efficiency of the vehicle. [54].

In Kim S. H. et. al. research, they using a $35 \mathrm{~kg}$ with diameter of $370 \mathrm{~mm}$ and thickness of $20 \mathrm{~mm}$ flywheel connected to the $1.5 \mathrm{~kW}, 4$ poles 3 phases brushless direct current motor as regenerative braking system to stipulate the movement of vehicles. Regenerative energy at 2500 RPM shows the maximum current of $69 \mathrm{~A}$ and the peak voltage of $11.868 \mathrm{~V}$ and constant current during the initial $7 \mathrm{~s}$. The voltage is reduced as the speed of rotation reduces. At 2500RPM, the time to completely stop takes about $16 \mathrm{~s}$. Since the regenerative braking energy is $2.8 \mathrm{~kJ}$ and the kinetic energy of flywheel is $11.57 \mathrm{~kJ}$, the efficiency is $24.2 \%$. While in the case of using the generator as a regenerative braking system, the maximum current generated is $60 \mathrm{~A}$ and the current is almost linearly gradually decrease. The voltage is almost constant at an average of $26.3 \mathrm{~V}$ during the regenerative braking. The regenerative braking last around $9 \mathrm{~s}$ and it is able to generate $7.39 \mathrm{~kJ}$. Because the kinetic energy of the flywheel which rotates at $2500 \mathrm{RPM}$ is $11.57 \mathrm{~kJ}$, the 
efficiency of the regenerative braking using a generator is $63.8 \%$. [55].

\subsection{Approaches Taken to Address Issue to Boost Mileage for EV and PHEV}

Regenerative braking system, the charging system that occurs during vehicles is slowing down and no force applied on acceleration pedal is used to prolong the mileage of EV and HEV. Since the regenerative braking system is a non-continuous charging system, it may not charge the batteries continuously. Therefore, a number of achievable mileage may not be as best as continuous charging.

There is another technology that can be suggested to boost the mileage of the EV and HEV, which is technology that is used to harvest wind energy, the wind turbine. A wind turbine uses a generator to convert kinetic energy to electricity. There are 2 types of generators commonly used on the vertical type of wind turbine design, which are ironcore and coreless electricity generator.

Since the coreless electricity generator has no cogging torque as well as starting torque, it is suitable to apply on the wind turbine. It is because there is no iron used in the stator construction and this in turns avoids direct magnetic attraction between rotor and stator [56].

For the axial-flux permanent magnet (AFPM) machine, it is a type of coreless generator configuration. It has less core material than the ironcore configuration. Moreover, AFPM machine has thin magnets, means that smaller than radial-flux counterparts [57]. In the D Ahmed and A Ahmad research, they proposed the usage of axial flux permanent magnet (AFPM) as a part of the wind turbine. The proposed generator's maximum efficiency at the rated operating conditions is $96.6 \%$ as compared to the value of $95.7 \%$ of the model of AFPM generator proposed [58]. Compare to Radial Flux Permanent Magnet (RFPM), AFPM has a smaller volume and lower mass with same power rating. [56].

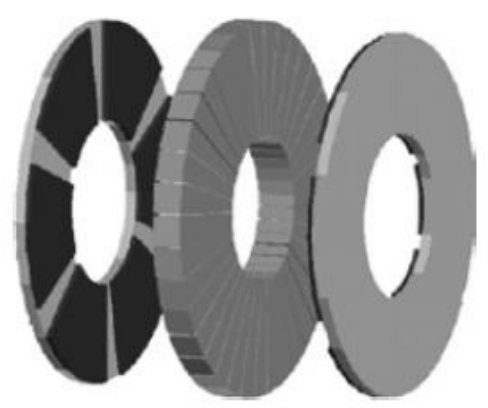

Figure 4. Slotless single-stator double-rotor APFM configuration

For AFPM generator, it is made up of 2 different parts, namely rotor and stator. There are five different types of combination for coreless type generator, which is a double-stator slotted type, a double-rotor slotted type, a single-sided axial flux permanent magnet with stator balance, a single-sided axial flux permanent magnet with rotor balance and a slotless single-stator double-rotor type. According to research elsewhere, two-sided axial flux permanent magnet type is better than one-sided axial flux permanent magnet [59]. High compactness and diskshaped profile make the model suitable for integration with a mechanical components such as wind turbine and internal combustion engine [60] as well as an additional generator for hybrid vehicles. This type of generator has no core and always has low inductance and thus, the increasing of current does not affect the machine performance [61]. It is cheap, easy to manufacture, and can produce up to hundreds kilo watts of power in multi disk operation. [62-63]. This type of generator also can operate on a wide variable range of frequency for optimal operation as well as provides an option to use the gearless operation [64].

For the iron-core type inductors, or it can be called as iron-core type generator, it has high electricity conductivity due to the usage of iron in the lamination of the core. Eddy currents cause additional core losses at high frequency and cause the magnetic field in the core become weaker and thus the main inductance decreases [65].

Because of the compactness and lightness as well as their high efficiency of the axial-flux coreless machine, they are among the most suitable candidates for many automotive applications [66]. It is because with the absence of core loss that cause by the iron core itself, the coreless stator axial-flux permanent-magnet (AFPM) machine can operate with higher efficiency compare to the conventional iron core machines [67]. With the ironless generator pair parallel with the regenerative braking system in the hybrid electric vehicles, the continuous charging for the battery or ultracapacitor expect to be achieved.

The advantages of the coreless type generator are summarized as follow:

- Simple winding,

- Low cogging torque and noise,

- Short axial length,

- High torque/volume ratio.

For the disadvantage of the coreless type generator, it can be summarized as follow:

- Lower torque/mass ratio,

- Larger outer diameter,

- Required large amount of permanent magnet and had to deal with structural instability,

- Difficult to maintain air gap for the large diameter rotor and stator,

- Difficult in the production of the stator core.

For the advantage of the cored type generator, it can be summarized as follow:

- Available in small size (depending on desired output),

- No moving parts.

The disadvantage of cored type generator are summarized as follow: 
- Eddy current production cause magnetic field in the core become weaker and main inductance decreases,

- Cogging effect cause by the usage of iron-core.

\subsection{Coreless Generator Design and Performance}

The permanent-magnet motors are gaining a reputation amongst the researchers because of their high-power density, high torque-to-inertia ratio, high efficiency [6869] as well as their robustness. [70]. A special characteristic of the axial-flux coreless permanent-magnet generator is the usage of the non-ferromagnetic holder to counteract the centrifugal forces acting on the magnet during the rotation of the rotor disks. [71]. Coreless configuration of axial-flux machine eliminates ferromagnetic material, thus, it eliminates the eddy current and hysteresis losses in the generator and it can be axially stacked so that the mechanical construction of the coreless axial-flux machine can be simplified, reduced the weight of the stator so that small size actuator is able to employ for winding shift [72]. But the usage of the back iron core in the design did not totally eliminate the cogging torque since the iron will somehow react with the electromotive force during operation.

The output differs with a different number of poles and which one is the strongest [73]. In the Kobayashi's research, they found out that 48 poles generate most magnetic field compare to 12 poles and 72 poles. The increase of poles number, the size of the coreless electricity generator is also increased. For the large-pole number, the diameter of the magnets and coils are fixed and limit the radial length of the active area which makes the generator has large radius but small active length. While for the small-pole number, low-power turbines tend to spin relatively fast, but as power increases and a reduction in speed is required, the number of poles should increase, which makes the radial length of the active area can be small compare to the radius of the stator. This kind of problem can be reduced by using trapezoidal or rectangular magnets whereby this helps the pole pitch and active length can be decoupled from each other [74].

Since the magnet carries an important role in making the generator an efficient one, the choice of making choose of magnet need to be considered well. Neodymium Iron Boron $(\mathrm{NdFeB})$ magnets are well known as the best magnet to be used. The continuous progress in the new high magnetic field rare-earth permanent magnets such as Neodymium Iron Boron $(\mathrm{NdFeB})$ magnet, has given the automotive sector a great opportunities on novel topologies for electric machine [75]. Greater availability and decreasing cost of highenergy permanent-magnet materials, which is Neodymium Iron Boron ( $\mathrm{NdFeB}$ ) magnet, has resulted in rapid permanent magnet generator development [76]. This modern magnetic material can easily be obtained in the market with different shapes and grades, thus the design of the usage for this magnet can be done easily. There is operating temperature within the magnet itself. Below the maximum operating temperature of the magnet, the magnet works perfectly fine, which is full magnetization, can be achieved. But when the temperature exceeds maximum operating temperature, the magnetic force depleted slowly until it reaches the Curie temperature, the magnet totally lost its magnetic force. When talking about the operating temperature of the magnet, it closely related to the Permeance Coefficient of the magnet. Permeance Coefficient is the calculation to measure the shape of magnet since the maximum operating temperature differs from the different shape of the magnet. Generally, the Permeance Coefficient will be higher if the magnet has long and small cross sectional area. [77].

The arrangement of the copper winding should be designed well so that maximum magnetic flux cutting can be done and maximum the efficiency of the generator itself. For the coreless electricity generator, coils of wire are used instead of multiple interconnected wires where the magnet rotates over them to produce the electricity. For instance, when the north pole of a magnet passing through a coil, the current flows in one direction, and when the South Pole passes over the coil, current flow through in the opposite direction. Based on the theories, the most electricity is generated while the magnetic field is at 90 degrees to the coil winding and no electricity is generated when the magnetic field is parallel to the coil. [78]. The magnet that currently at the North Pole is pushing upward on the left radial leg of the coil and at the same time, the magnet that currently at the South Pole is pushing downward on the right radial leg. These two clockwise motions cause the electricity being generated. Notice that if both radial legs are pushing at the same direction, for example, left and right radial leg is pushing upward together at the same time, the motion is canceled out each other and thus, no electricity is generated. That is the reason which it is essential to arrange the magnet poles alternatively so that the motion will not cancels out each other. The coil is then connected with the threephase power connection for maximum electricity output. In order to makes pole pitch equal to diameter of coil, the thickness of the coil cannot be increased more than $33 \%$ of pole pitch because of geometrical relation, or simply say, the distance between coils must be equal to $133 \%$ of the pole pitch. [78].

In order to eliminate the cogging torque as well as the counter electromotive force (CEMF), the core element, which is the iron had to be fully eliminated from the generator. For the coreless electricity generator, although the minimum usage of the core, but still, it is not perfect since the cogging torque and CEMF still significance within the generator itself. To overcome such problem facing by the most generator, the ironless configuration of the generator is seen as a promising solution to be considered. When talking about ironless configuration, there will be no core material or iron used in both rotor and stator. The cogging torque and CEMF can be minimized and thus, increase the efficiency of the system itself. 


\section{Conclusion}

One of the weaknesses of PHEV and EV is the charging system. Just as explained earlier, the regenerative braking, the electricity recharging system within PHEV and EV, only can perform its function during the vehicles is slowing down as well as without foot on the accelerator. In other words, the electric charging system is inconstant, unsustainable and non-continuous. By applying another generator which is parallel with the electricity recharging system, the continuous charging can be achieved. Since the coreless electricity generator has less counter electromotive force (CEMF) comparing to cored electricity generator and no cogging torque, the application of the coreless electricity generator parallel to the regenerative braking system is the more suitable comparing to cored electricity generator.

The coreless electricity generators currently already exist. Some of them have different numbers of poles, while some of them have a closer gap between rotors and different in size. Although there are some differences in different researcher's coreless electricity generator, there are some similarities - these coreless electricity generators have lesser cogging effects and CEMF compare to cored electricity generator. Since the coreless electricity generator is still facing cogging effect and CEMF, it is suggested that using ironless configuration of the generator can minimized the cogging effect as well as CEMF to the lowest level since this configuration did eliminate the usage of iron in both rotor and stator, which believe that this system can bring better continuous charging experience for the HEV and EV users in the future.

\section{References}

[1] Pollet, B. G., Staffell, I., \& Shang, J. L. (2012). Current status of hybrid, battery and fuel cell electric vehicles: From electrochemistry to market prospects. Electrochimica Acta, 84, 235-249. doi: 10.1016/j.electacta.2012.03.172

[2] Lv, C., Zhang, J., Li, Y., \& Yuan, Y. (2015). Mechanism analysis and evaluation methodology of regenerative braking contribution to energy efficiency improvement of electrified vehicles. Energy Conversion and Management, 92, 469-482.

[3] Jorgensen, K. (2008). Technologies for electric, hybrid and hydrogen vehicles: Electricity from renewable energy sources in transport. Utilities Policy, 16(2), 72-79.

[4] van Vliet, O., Brouwer, A. S., Kuramochi, T., van den Broek, M., \& Faaij, A. (2011). Energy use, cost and $\mathrm{CO} 2$ emissions of electric cars. Journal of Power Sources, 196(4), 2298-2310. doi: 10.1016/j.jpowsour.2010.09.119

[5] Clarke, P., Muneer, T., \& Cullinane, K. (2010). Cutting vehicle emissions with regenerative braking. Transportation Research Part D: Transport and
Environment, 15(3), 160-167. doi: 10.1016/j.trd.2009.11.002

[6] Zhang, Z., Chen, A., Matveev, A., Nilssen, R., \& Nysveen, A. (2013). High-power generators for offshore wind turbines. Energy Procedia, 35, 52-61.

[7] Mahmoudi, A., Kahourzade, S., Rahim, N. A., Ping, H. W., \& Uddin, M. N. (2013). Design and prototyping of an optimised axial-flux permanentmagnet synchronous machine. IET Electric Power Applications, 7(5), 338-349.

[8] T\&E, CO2 Emissions from New Cars-Position paper in response to the European Commission proposal, 2008.

[9] De Almeida, P., \& Silva, P. D. (2009). The peak of oil production-timings and market recognition. Energy Policy, 37(4), 1267-1276.

[10] Plunkett Research Ltd. (2011). Automotive Industry Overview. $\quad$ Retrieved from http://tinyurl.com/4yhd93u

[11]Dunn, S. (2002). Hydrogen futures: toward a sustainable energy system.International journal of hydrogen energy, 27(3), 235-264.

[12] Culley, M. R., Carton, A. D., Weaver, S. R., OgleyOliver, E., \& Street, J. C. (2011). Sun, Wind, Rock and Metal: Attitudes toward Renewable and Nonrenewable Energy Sources in the Context of Climate Change and Current Energy Debates. Current Psychology, 30(3), 215-233. doi: 10.1007/s12144011-9110-5

[13] Greene, D. L. (2010). Measuring energy security: Can the United States achieve oil independence?. Energy policy, 38(4), 1614-1621.

[14]Romm, J. (2006). The car and fuel of the future. Energy Policy, 34(17), 2609-2614.

[15] Van Mierlo, J., Maggetto, G., \& Lataire, P. (2006). Which energy source for road transport in the future? A comparison of battery, hybrid and fuel cell vehicles. Energy Conversion and Management, 47(17), 2748-2760.

[16] Johansson, B., \& Åhman, M. (2002). A comparison of technologies for carbon-neutral passenger transport. Transportation Research Part D: Transport and Environment, 7(3), 175-196.

[17] Van Vliet, O. P., Kruithof, T., Turkenburg, W. C., \& Faaij, A. P. (2010). Techno-economic comparison of series hybrid, plug-in hybrid, fuel cell and regular cars.Journal of Power Sources, 195(19), 6570-6585.

[18] Silva, C. (2011). Electric and plug-in hybrid vehicles influence on $\mathrm{CO}<\mathrm{sub}>2</$ sub $>$ and water vapour emissions. International Journal of Hydrogen Energy, 36(20), 13225-13232.

[19]Department of Energy, United States of America. One Million Electric Vehicles By 2015. Retrieved from

http://www1.eere.energy.gov/vehiclesandfuels/pdfs/1 million_electric_vehicles_rpt.pdf

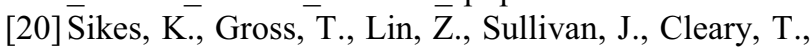
\& Ward, J. (2010). Plug-in hybrid electric vehicle market introduction study: final report (No. ORNL/TM-2009/019). Oak Ridge National Laboratory (ORNL). 
[21] The Central People's Government of the People's Republic of China. Retrieved from http://www.gov.cn/zwgk/201207/09/content_2179032.htm

[22] Green eMotion: Development and Demonstration of a Unique and User-Friendly Framework for Green Electromobility in Europe; EU 7th Framework Programme; CODEMA-City of Dublin Energy Management Agency Ltd.: Dublin, Ireland, 2011.

[23] Kempton, W., \& Kubo, T. (2000). Electric-drive vehicles for peak power in Japan. Energy Policy, 28(1), 9-18.

[24] Won, J. R., Yoon, Y. B., \& Lee, K. J. (2009, October). Prediction of electricity demand due to PHEVs (Plug-In Hybrid Electric Vehicles) distribution in Korea by using diffusion model. In Transmission \& Distribution Conference \& Exposition: Asia and Pacific, 2009 (pp. 1-4). IEEE.

[25] Su, W., Eichi, H., Zeng, W., \& Chow, M. Y. (2012). A survey on the electrification of transportation in a smart grid environment. Industrial Informatics, IEEE Transactions on, 8(1), 1-10.

[26] Toyota. Toyota Prius. Retrieved from http:/www.toyota.com.my/prius/

[27] Volkswagen. Volkswagen Jetta. http://www.vw.com/models/jetta/

[28]Honda. Honda CR-Z. Retrieved from http://www.honda.com.my/model/overview/crz

[29] Chevrolet. Chevrolet Volt. Retrieved from http://www.chevrolet.com/volt-electric-car.html

[30]BMW. $B M W$ i8. Retrieved from http://www.bmw.com/com/en/newvehicles/i/i8/2014/ showroom/index.html

[31]Nissan. Nissan LEAF. Retrieved from http://www.nissanusa.com/electric-cars/leaf/

[32] Tesla Motors. Model $S$. Retrieved from http://www.teslamotors.com/models

[33] Case Study: Toyota Hybrid Synergy Drive. Retrieved from

http://www.ae.pwr.wroc.pl/filez/20110606092430_H EV_Toyota.pdf

[34] Tanaka, Y., Nakaoka, H., Mizutani, Y., \& Nakamura, E. (2014). U.S. Patent No. 8,733,849. Washington, DC: U.S. Patent and Trademark Office.

[35] Toyota Prius Vehicle Throttle and Brake Systems: Myth VS. Fact. Retrieved from http://pressroom.toyota.com/article_print.cfm?article $\mathrm{id}=1927$

[36] $\bar{C}$ Courtesy of Honda. (2015). The Honda Hybrid system: the engine is the main power source. Retrieved from http://world.honda.com/automobiletechnology/IMA/ima02/

[37] Courtesy of BMW. (2015). BMW ACTIVE HYBRID. Retrieved from http://www.bmw.com/com/en/insights/technology/ef ficientdynamics/phase_2/bmw_activehybrid/index.ht $\mathrm{ml}$

[38] Tanaka, N. (2011). Technology roadmap: Electric and plug-in hybrid electric vehicles. International Energy Agency, Tech. Rep.
[39] Duvall, M., Knipping, E., Alexander, M., Tonachel, L., \& Clark, C. (2007). Environmental assessment of plug-in hybrid electric vehicles. EPRI, July.

[40] Malaysian Automotive Association (MAA). (2014). National Automotive Policy (NAP) 2014. Retrieved from http://www.maa.org.my/pdf/NAP 2014 policy.pdf

[41] Malaysia Automotive Institute (MAI). (2014). Malaysia Technology Roadmap 2014. Retrieved from http://mai.org.my/v3

[42]Accenture. (2011). Plug-in Electric Vehicles: Changing Perceptions, Hedging Bets. Accenture End-consumer Survey on the Electrification of Private Transport.

ACC11-0320/7-1792, 48 pp. Retrieved from http://www.accenture.com/Microsites/accenturesmart solutions-

electricvehicles/Documents/Accenture Plugin_Electric_Vehicle_Consumer_Perceptions_FINAL .PDF

[43] Sovacool, B. K., \& Hirsh, R. F. (2009). Beyond batteries: An examination of the benefits and barriers to plug-in hybrid electric vehicles (PHEVs) and a vehicle-to-grid (V2G) transition. Energy Policy, 37(3), 1095-1103.

[44] Offer, G. J., Howey, D., Contestabile, M., Clague, R., \& Brandon, N. P. (2010). Comparative analysis of battery electric, hydrogen fuel cell and hybrid vehicles in a future sustainable road transport system. Energy Policy, 38(1), 24-29.

[45]Chan, C. (2007). The state of the art of electric, hybrid, and fuel cell vehicles. Proceedings of the IEEE, 95(4), 704-718.

[46] Sovran, G., \& Blaser, D. (2006). Quantifying the potential impacts of regenerative braking on a vehicle's tractive-fuel consumption for the US, European, and Japanese driving schedules (No. 2006-01-0664). SAE Technical Paper.

[47]Huang, S., \& Infield, D. (2010, October). The impact of domestic Plug-in Hybrid Electric Vehicles on power distribution system loads. In Power System Technology (POWERCON), 2010 International Conference on (pp. 1-7). IEEE.

[48] Su, W., \& Chow, M. Y. (2012). Performance evaluation of an EDA-based large-scale plug-in hybrid electric vehicle charging algorithm. Smart Grid, IEEE Transactions on, 3(1), 308-315.

[49] Su, W., \& Chow, M. Y. (2012). Computational intelligence-based energy management for a largescale PHEV/PEV enabled municipal parking deck.Applied Energy, 96, 171-182.

[50] Su, W., Wang, J., Zhang, K., \& Chow, M. Y. (2012, October). Framework for investigating the impact of PHEV charging on power distribution system and transportation network. In IECON 2012-38th Annual Conference on IEEE Industrial Electronics Society (pp. 4735-4740). IEEE.

[51]Zhang, J., Lv, C., Gou, J., \& Kong, D. (2012). Cooperative control of regenerative braking and hydraulic braking of an electrified passenger car.Proceedings of the Institution of Mechanical 
Engineers, Part D: Journal of Automobile Engineering, 0954407012441884.

[52] Gao, Y., \& Ehsani, M. (2001). Electronic Braking System of EV and HEV---Integration of Regenerative Braking, Automatic Braking Force Control and ABS(No. 2001-01-2478). SAE Technical Paper.

[53] Robert Bosch GmbH. (2011). Chassis Systems Control, Regenerative Braking System. Retrieved from www.bosch-automotivetechnology.com

[54] Junzhi, Z., Yutong, L., Chen, L., \& Ye, Y. (2014). New regenerative braking control strategy for reardriven electrified minivans. Energy Conversion and Management, 82, 135-145.

[55] Kim, S. H., Kwon, O. J., Hyon, D., Cheon, S. H., Kim, J. S., Kim, B. H., . . . Oh, B. S. (2013). Regenerative braking for fuel cell hybrid system with additional generator. International Journal of Hydrogen Energy, 38(20), 8415-8421. doi: 10.1016/j.ijhydene.2013.04.020

[56] Gieras, J. F., Wang, R. J., \& Kamper, M. J. (2008). Axial flux permanent magnet brushless machines (Vol. 1). New York, NY: Springer.

[57] Mahmoudi, A., Rahim, N. A., \& Hew, W. P. (2011). Axial-flux permanent-magnet machine modeling, design, simulation, and analysis. Scientific Research and Essays, 6(12), 2525-2549.

[58] Ahmed D. and Ahmad A. (2013). An optimal design of coreless direct-drive axial flux permanent magnet generator for wind turbine. Journal of Physics: Conference Series 439 (2013) 012039

[59] Li, H., \& Chen, Z. (2008). Overview of different wind generator systems and their comparisons. IET Renewable Power Generation, 2(2), 123-138.

[60] Wang, R. J., Kamper, M. J., Van der Westhuizen, K., \& Gieras, J. F. (2005). Optimal design of a coreless stator axial flux permanent-magnet generator.Magnetics, IEEE Transactions on, 41(1), 55-64.

[61]Fitzgerald, A. E., \& Kingsley, C. (1961). Electric machinery: the dynamics and statics of electromechanical energy conversion. McGraw-Hill.

[62] Virtic, P., Pisek, P., Marcic, T., Hadziselimovic, M., \& Stumberger, B. (2008). Analytical analysis of magnetic field and back electromotive force calculation of an axial-flux permanent magnet synchronous generator with coreless stator.Magnetics, IEEE Transactions on, 44(11), 4333-4336.

[63] Hwang, C. C., Li, P. L., Chuang, F. C., Liu, C. T., \& Huang, K. H. (2009). Optimization for reduction of torque ripple in an axial flux permanent magnet machine. Magnetics, IEEE Transactions on, 45(3), 1760-1763.

[64]Zhang, S., Tseng, K. J., Vilathgamuwa, D. M., Nguyen, T. D., \& Wang, X. Y. (2011). Design of a robust grid interface system for PMSG-based wind turbine generators. Industrial Electronics, IEEE Transactions on, 58(1), 316-328.

[65] Reggiani, U., Grandi, G., Sancineto, G., Serra, G. (2000). Comparison Between Air-Core and Laminated Iron-Core Inductors in Filtering
Applications for Switching Converters. IEEE-CIEP Conference, Acapulco, (MEX), October 15-19, 2000

[66] Mirzaei, M., Mirsalim, M., \& Abdollahi, S. E. (2007). Analytical modeling of axial air gap solid rotor induction machines using a quasi-three-dimensional method. Magnetics, IEEE Transactions on, 43(7), 3237-3242.

[67]Del Ferraro, L., Giulii Capponi, F., Terrigi, R., Caricchi, F., \& Honorati, O. (2006, October). Ironless axial flux PM machine with active mechanical flux weakening for automotive applications. In Industry Applications Conference, 2006. 41st IAS Annual Meeting. Conference Record of the 2006 IEEE (Vol. 1, pp. 1-7). IEEE.

[68] Lombard, N. F., \& Kamper, M. J. (1999). Analysis and performance of an ironless stator axial flux PM machine. Energy Conversion, IEEE Transactions on, 14(4), 1051-1056.

[69]Breton, C., Bartolome, J., Benito, J. A., Tassinario, G., Flotats, I., Lu, C. W., \& Chalmers, B. J. (2000). Influence of machine symmetry on reduction of cogging torque in permanent-magnet brushless motors. Magnetics, IEEE Transactions on, 36(5), 3819-3823.

[70] Chen, J. L., \& Liu, T. H. (2012). Implementation of a predictive controller for a sensorless interior permanent-magnet synchronous motor drive system.Electric Power Applications, IET, 6(8), 513525.

[71] Hosseini, S. M., Agha-Mirsalim, M. \& Mirzaei, M. (2008). Design, Prototyping, and Analysis of a Low Cost Axial-Flux Coreless Permanent-Magnet Generator. IEEE Transaction on Magnetics, Vol. 44, No. 1, January 2008

[72] Javadi, S., \& Mirsalim, M. (2010). Design and analysis of $42-\mathrm{V}$ coreless axial-flux permanentmagnet generators for automotive applications. Magnetics, IEEE Transactions on, 46(4), 1015-1023.

[73] Kobayashi, H., Doi, Y., Miyata, K. and Minowa, T. (2009). Design of axial-flux permanent magnet coreless generator for the multi-megawatts wind turbines. EWEC2009.

[74]Bumby, J. R., \& Martin, R. (2005). Axial-flux permanent-magnet air-cored generator for smallscale wind turbines. IEE Proceedings-Electric Power Applications, 152(5), 1065-1075.

[75]Mo, W., Zhang, L., Shan, A., Cao, L., Wu, J., \& Komuro, M. (2008). Improvement of magnetic properties and corrosion resistance of $\mathrm{NdFeB}$ magnets by intergranular addition of $\mathrm{MgO}$. Journal of Alloys and Compounds,461(1), 351-354.

[76] Chan, T. F., \& Lai, L. L. (2007). An axial-flux permanent-magnet synchronous generator for a direct-coupled wind-turbine system. Energy Conversion, IEEE Transactions on, 22(1), 86-94.

[77]K\&J Magnetics, Inc. Temperature and Neodymium Magnet. $\quad$ Retrieved from http://www.kjmagnetics.com/blog.asp?p=temperatur e-and-neodymium-magnets

[78] Drazikowski, L., \& Koczara, W. (2011). Permanent magnet disk generator with coreless windings. 
UTP-UMP SES 2015

COMPEL: The International Journal for Computation and Mathematics in Electrical and Electronic Engineering, 31(1), 108-118. 